\title{
VIVA O ESPORTE: UMA ANÁLISE DA POLÍTICA PÚBLICA DE ESPORTES DE UM MUNICÍPIO DO INTERIOR DO ESTADO DO RIO DE JANEIRO
}

\author{
Mario Mecenas Pagani* \\ Fernando Antônio Leite Cabral Loureiro** \\ Sérgio Henrique de Mattos Machado*** \\ Ludmila Gonçalves da Matta****
}

\begin{abstract}
Resumo
Políticas públicas são diretrizes da ação do poder público junto a sociedade, normas e procedimentos para as relações dos atores sociais e o Estado. O objetivo deste estudo foi descrever e analisar as políticas públicas de esporte da Fundação Municipal de Esporte (FME), da cidade de Campos dos Goytacazes-RJ. A metodologia utilizada caracterizou-se como descritiva. Os resultados do estudo indicam que o município estrutura o seu trabalho por meio da FME e que ela apresenta resultados expressivos nas políticas de incentivo ao esporte. Os programas de esporte oferecidos pelo município sofreram significativa redução no número de profissionais de educação física de 2016 a 2018, entretanto, houve aumento no número de participações e ofertas de modalidades esportivas nos programas. Em 2016, eram 1.200 participantes em 9 modalidades e em 2018 foram 15.000 participantes e 41 modalidades. Por meio do estudo, foi possível concluir que a política pública do Município de Campos dos Goytacazes voltada para o esporte proporciona excelentes resultados para a saúde e bem-estar da população refletindo, inclusive, na redução com os gastos em saúde.
\end{abstract}

Palavras-chave: Políticas Públicas. Esporte. Lazer.

\footnotetext{
* Doutorando em Planejamento Regional Gestão da Cidade pela Universidade Cândido Mendes (UCAM) - Campos de Goytacazes/ RJ. Mestre em Educação Física. E-mail: mario.pagani@iff.edu.br

** Mestrando em Planejamento Regional e Gestão da Cidade pela Universidade Cândido Mendes (UCAM) - Campos de Goytacazes/ RJ. E-mail: fernandoantonioloureiro@gmail.com

*** Doutorando em Planejamento Regional Gestão da Cidade pela Universidade Cândido Mendes (UCAM) - Campos de Goytacazes/ RJ. Mestre em Pesquisa Operacional e Inteligência Artificial. E-mail: shmmachado@gmail.com

**** Doutora em Sociologia Política pela Universidade Estadual do Norte Fluminense Darcy Ribeiro. Mestre em Políticas Sociais pela Universidade Federal Fluminense. Docente do Mestrado e Doutorado em Planejamento Regional e Gestão da Cidade da Universidade Cândido Mendes (UCAM). E-mail: ludmatta@yahoo.com.br
} 


\section{Introdução}

Compreender o campo da política pública e, especialmente, as políticas públicas voltadas para o esporte tem sido um crescente na produção acadêmica nacional. Entretanto, quando se trata dessa questão torna-se imprescindível entender a heterogeneidade do território brasileiro e as peculiaridades que os desenhos das políticas de esporte assumem no País. Dessa forma, esse trabalho apresenta uma análise da política pública de esporte implementada no município de Campos dos Goytacazes/RJ.

A cidade de Campos é reconhecida nacionalmente pela produção de petróleo, extraído da Bacia de mesmo nome. Nos últimos anos, os municípios confrontantes com as bacias petrolíferas do norte fluminense têm sido premiados com vultosos recursos provenientes do recebimento de royalties e participações especiais. No entanto, por outro lado, vários estudos têm apontando o mau uso desses recursos (BRAGA; SERRA; TERRA, 2007).

Nesse sentido, um exemplo a ser apontado é o fraco desempenho do Município de Campos dos Goytacazes no Índice de Desenvolvimento da Educação Básica (IDEB). No ano de 2017, Campos figurou a 79a posição dentre os 91 municípios do estado do Rio de Janeiro (INEP, 2018). Portanto, entendendo que o esporte é uma vertente que se associa à educação no processo de socialização e formação do sujeito social que a análise dos investimentos públicos nesse setor se faz relevante.

Dessa forma, o desenvolvimento desse trabalho trará uma análise dos programas de esporte implementados pelo município em questão, a partir no biênio 2017-2018 - início de uma nova gestão municipal. Buscarse-á responder as seguintes perguntas: Quais são as políticas públicas de esporte desenvolvidas pelo município de Campos dos Goytacazes? Quais as atividades que estão sendo desenvolvidas atualmente? Qual é o investimento financeiro do município nessas políticas públicas? Quem e quantos são os beneficiários dessas políticas?

O referencial teórico e o arcabouço da pesquisa foram construídos a partir de uma pesquisa bibliográfica e de levantamento de dados da gestão municipal, além de entrevista com o atual presidente da Fundação Municipal de Esporte. A metodologia utilizada caracterizou-se como descritiva.

Para analisar e descrever o programa de esportes oferecido pela Prefeitura de Campos dos Goytacazes também foi utilizado o método de avaliação desenvolvido por Stufflebean, de 1968 a 1971: Contexto, de Insumos, de Processos e de Produtos (CIPP) (STUFLEBEAN, 2003). No entanto, é importante salientar que este estudo apresenta resultados parciais, tendo em vista que as informações levantadas fazem parte de uma das fases do projeto de tese de doutoramento do autor. 


\section{Política pública de esporte}

Os conceitos de esporte e atividade física por vezes se confundem no imaginário social. No entanto, a diferença entre eles está no fato de que o esporte é uma atividade física organizada, ou seja, qualquer esporte é atividade física, mas nem toda atividade física é esporte. Qualquer movimento do corpo que provoque gastos de energia é uma atividade física, seja levantar, sentar-se, andar, carregar coisas etc. Muitas definições de esporte incluem a noção que ele é uma atividade física. Em outras palavras, o esporte envolve o uso de atividades motoras, proeza física ou esforço físico. Isso já delimita o conceito, mas diferentes atividades físicas claramente variam na sua caracterização de habilidade motora, proeza ou esforço (BARBANTI, 2006).

A prática de atividades físicas é fundamental da infância até a terceira idade. Não existe exercício ideal, mas é preciso respeitar a individualidade, o desejo, prazer e a aptidão física de cada indivíduo. Os benefícios do esporte para a infância, por exemplo, são importantes não apenas para o desenvolvimento físico e motor como também para o desenvolvimento social das crianças. A partir de suas regras e condições, as crianças conseguem compreender formas de relacionarem-se com os outros, trocando experiências, competindo e ajudando-se mutuamente.

Hedley (2004) afirma que, com o advento da tecnologia, cada vez mais as pessoas, e entre elas as crianças e os adolescentes, são expostas diariamente ao mínimo de esforço físico, fazendo uso constante dos videogames, controles remotos, celulares e tantos outros recursos. Isso ocasiona uma redução significativa no gasto energético e movimentos corporais diários e pode desenvolver doenças em virtude da hipocinesia. Caracteriza-se, assim, o sedentário, fazendo que a perda de hábitos saudáveis e a prática de esportes prejudiquem o desenvolvimento psicomotor, originando problemas físicos e orgânicos.

Para Andersen et al. (2009) na Europa e em vários países ocidentais tem havido uma preocupação constante com nível de aptidão física dos escolares, classificado como baixo. No Brasil, Masson et al. (2005) também encontraram o baixo nível de atividade física em várias faixas, inclusive dentre os adolescentes. Em outro estudo realizado por Silva (2005), com estudantes da cidade de Maceió, foi verificado que 93,5\% da população avaliada estavam classificados como sedentários. Em outras regiões do Brasil, foi desenvolvida a mesma pesquisa e verificou-se que nos estados do Rio de Janeiro, Rio Grande do Sul, Paraná e Santa Catarina, os níveis de atividade física dos adolescentes é baixo.

Diante desse contexto, das lutas promovidas pela sociedade civil e por profissionais da área é importante destacar que as práticas desportivas receberam um capítulo especial no texto da Constituição Federal, de 1988: 
Art. 217. É dever do Estado fomentar práticas desportivas formais e não formais, como direito de cada um, observados:

$\S 3^{\circ}$ - O Poder Público, incentivará o lazer, como forma de promoção social. (BRASIL, 1988).

Além dessa legislação o marco para política pública de esporte foi a aprovação da Política Nacional do Esporte (PNE) em 2005. A PNE estabeleceu quatro princípios que devem nortear as políticas públicas de esporte no País: da reversão do quadro atual de injustiças, exclusão e vulnerabilidade social; do esporte e do lazer como direito de cada um e dever do Estado; da universalização e da inclusão social; da democratização da gestão e da participação (BRASIL, 2005).

A partir desse referencial estabeleceu-se que as políticas públicas de esporte devem incorporar o campo social contribuindo na melhoria de indicadores sociais além de buscar a efetividade no combate à exclusão e na minimização da desigualdade social, contribuindo assim para o desenvolvimento social.

Buscando identificar se esses indicadores estavam sendo contemplados nas políticas públicas de esporte, várias pesquisas começaram a ser desenvolvidas no país. Levantamentos identificaram que as pesquisas em políticas públicas no Brasil caracterizaram-se, na sua maioria, por exposições empíricas. De acordo com Melo (1999), as características da pesquisa brasileira em políticas públicas dificultam uma acumulação do conhecimento, pois há uma proliferação horizontal de estudos de caso e/ ou relatos de experiência. Os estudos de Starepravo, (2007); Starepravo e Mezzadri (2007) também identificaram que a maioria dos estudos que abordaram o tema políticas públicas de esporte e lazer foram caracterizados como relatos de experiência.

No entanto, vislumbra-se a possibilidade de produção do conhecimento de políticas públicas de esporte a partir do surgimento, em 2003, dos Centros de Desenvolvimento de Esporte Recreativo e de Lazer, a Rede CEDES. O conhecimento alcançado pela Rede está voltado para os gestores do esporte e lazer e possibilita a aproximação do subcampo científico/acadêmico ao subcampo político/burocrático (STAREPRAVO, 2018).

No Brasil, houve também a criação da Rede Cenesp, composta de centros de desenvolvimento de pesquisa científica e tecnológica na área de esporte, treinamento e aperfeiçoamento de atletas. A partir da criação desses grupos de pesquisas, cada uma buscando informações dentro da sua área de atuação, mais pesquisas começaram a ser desenvolvidas no País (STAREPRAVO et al., 2014). Cabe ressaltar que ambas as Redes foram criadas a partir de uma estrutura garantida pelo Ministério da Educação e que trabalham com abordagens distintas, como esporte recreativo e lazer e esporte de rendimento. 
Em um se seus estudos, Starepravo (2014) verificou que, apesar do subcampo político/burocrático não estar sendo apropriado pelo conhecimento produzido pelo subcampo científico/acadêmico das políticas públicas de esporte e lazer, suas apropriações parecem ser o desejo de diversos gestores esportivos.

Tendo em vista a necessidade dos gestores, percebeu-se um aumento na produção de estudos sobre o esporte enquanto fenômeno social. A expansão, de acordo com Bento (2013), deve-se a uma ressignificação do esporte enquanto um fenômeno polissêmico e polimórfico. Isso possibilita diferentes aplicações de acordo com as necessidades dos grupos que a utilizam, como também sua aplicação em disciplinas acadêmicas variadas.

Outros estudos utilizados como referência buscaram identificar políticas públicas de esportes do Governo Federal. Dentre os temas pesquisados o Programa Segundo Tempo (PST) foi identificado por Santos, Starepravo e Souza Neto (2015) como um "vazio assistencial". Eles analisaram a participação dos municípios da região Nordeste nesse Programa e identificaram que ao longo de dez anos as cidades nordestinas não tiveram acesso a ele. Concluíram, portanto, que um programa que se propõe a democratizar o esporte e atender prioritariamente populações vulneráveis, a existência, por si, só, do vazio assistencial, depõe contra seus objetivos.

No âmbito da cidade de Campos dos Goytacazes, a política pública de esporte está prevista na Lei Orgânica Municipal (LOM), promulgada em 1990, revisada, publicada em 26/08/2014 e republicada em 29/08/2014, a qual reserva uma seção específica ao desporto e ao lazer. Na seção III do documento, o desporto e o lazer são expressos como direito de todos e o lazer é proposto como forma de integração social. O artigo 241 da mesma lei estabelece que os recursos orçamentários destinados para este setor devem priorizar: I- o esporte educacional, o esporte comunitário e, na forma da lei: o esporte de alto rendimento; II- o lazer popular. (CAMPOS DOS GOYTACAZES, 2014).

O parágrafo $1^{\circ}$ do artigo 241 da LOM ainda expõe que "O município estimulará e apoiará as entidades e associações da comunidade dedicadas às práticas esportivas, vedada a subvenção a entidades desportivas profissionais." (CAMPOS DOS GOYTACAZES, 2014).

E, na esteira da PNE, foi lançada em 2011 a Política Municipal de Esporte e Lazer (PMEL), por meio da Lei Municipal n. 8.240/2011. O PMEL prioriza aquilo que já foi estabelecido no âmbito da política nacional, reforçando o compromisso com os princípios básicos de "[...] estimular, desenvolver e fomentar, práticas de esporte, lazer e atividades físicas para o desenvolvimento de potencialidades do ser humano e de qualidade de vida, visando bem-estar, promoção social e inserção na sociedade, consolidando sua cidadania.” (CAMPOS DOS GOYTACAZES, 2011). 


\section{Campos dos Goytacazes: indicadores e análises}

No ano de 2018, ao Município de Campos dos Goytacazes teve uma população estimada de 463.731 habitantes. Quando se analisa os indicadores de saúde, por exemplo, Campos teve uma taxa de mortalidade infantil acima da média nacional. Em 2014, enquanto a média nacional era de 13,3 óbitos por cada 1.000 nascidos vivos em Campos a taxa foi de 14,77 (IBGE-CIDADES, 2018). O que é inverso quando se analisa o PIB per capta. Enquanto o Brasil registrou um PIB per capta de R\$29.347,00 em 2015, Campos registrou um PIB per capta de $\mathrm{R} \$ 70.700,19$ nesse mesmo período. Ou seja, mais que o dobro da média nacional.

O PIB elevado pode ser explicado em razão do recebimento dos royalties do petróleo mais as participações especiais (valores pagos quando o poço de petróleo tem alta produtividade). Em 2013, Campos recebeu em royalties e participações especiais $\mathrm{R} \$ 1$ 1.303.272.971,45 (INFOROYALTIES, 2018). Entretanto, desde 2014 esse cenário vem se modificando. A brusca queda do preço do barril de petróleo em 2013 somado à crise e às mudanças de investimento da Petrobrás, priorizando o pré-sal, vem fazendo essa receita cair consideravelmente. De acordo com o Inforoyalties (2018), em 2017 o Município de Campos recebeu $\mathrm{R} \$$ 470.860.676,51.

Quanto à educação, como já demonstrado, o desempenho no Índice de avaliação da Educação Básica (IDEB) tem sido muito desfavorável. Uma das explicações para esse fraco desempenho, como demonstra os estudos de Matta, Berçot e Rangel (2018), está relacionada a baixa qualificação dos professores da educação municipal. Apenas 40\% dos professores do primeiro segmento ( $1^{\circ}$ ao $5^{\circ}$ ano do ensino fundamental) possuem apenas a formação no ensino médio.

Quando se trata da política de esporte, observa-se que o município, no contexto das rendas petrolíferas, possui um orçamento significativo para a pasta, demonstrado na tabela a seguir:

Tabela 1 - Orçamento anual da FME.

\begin{tabular}{ccccc}
\hline Ano & 2014 & 2015 & 2016 & 2017 \\
\hline Valores & $\mathrm{R} \$ 6.000 .000,00$ & $\mathrm{R} \$ 7.445 .000,00$ & $\mathrm{R} \$ 6.213 .000,00$ & $\mathrm{R} \$ 4.324 .900,00$ \\
\hline
\end{tabular}

Fonte: PMCG. Transparência-campos, 2018.

Esse orçamento é superior a muitos orçamentos de educação de municípios com o perfil semelhante ao de Campos. Mas como tem sido gasto esse orçamento? Viu-se emergir na gestão pública no Brasil, desde os anos 1990, o surgimento do chamado "terceiro setor", movimento liderado por Organizações não Governamentais (ONGs), fundações públicas e privadas, empresas e outras organizações. 
Curiosamente esse modelo que, em princípio, visava a articular a sociedade e os recursos privados para fomentar a política pública, em Campos dos Goytacazes, no contexto das rendas petrolíferas, essas instituições privadas eram utilizadas para captar recursos públicos. Isso é demonstrado por meio do estudo realizado por Borba e Lira (2015) que apresenta o recebimento das entidades privadas, fundações e ONGs de grande parte dos recursos destinados à pasta do esporte. Isso é evidenciado na figura a seguir.

Figura 1 - Entidades que receberam repasses da FME.

\begin{tabular}{|c|c|c|}
\hline \multicolumn{3}{|c|}{ CONVENIOS. SUBVENCOES E TERMOS OE CONTRIBUICAO } \\
\hline ENTIOADE & TEMPPO & VALOR TOTAL \\
\hline 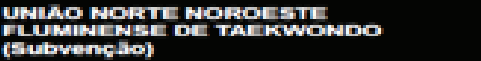 & OG MESEE & RSS 140350,00 \\
\hline $\begin{array}{l}\text { UNIAO NORTE NOROESTE } \\
\text { FLUMANENSE DE TAEKWWONDO } \\
\text { (CONVENIO) }\end{array}$ & OE MESES & RS $59.055,00$ \\
\hline 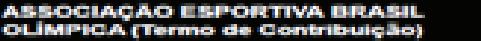 & 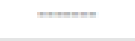 & RS $24,010,00$ \\
\hline 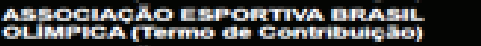 & OS MESES & REs $156.400,00$ \\
\hline 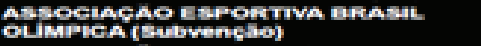 & 96 MESES & Rs 66.000 .00 \\
\hline 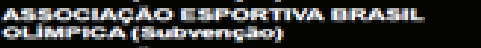 & 31 MESES & Rs 5.416 .224 .36 \\
\hline $\begin{array}{l}\text { AsSOCLACAO ESPORTIVA DRASIL } \\
\text { OLIMPICA (SUbvencalo) }\end{array}$ & O5 Misers & RS 70.006 .65 \\
\hline 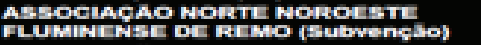 & OG ME:SE & RS 70.000 .00 \\
\hline 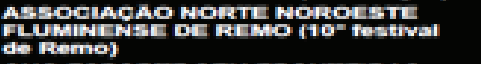 & $+\cdots$ & RS $18.198,60$ \\
\hline 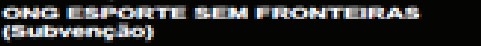 & OQ MESEB & RS $120,000,00$ \\
\hline 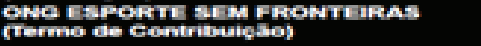 & OZ MESES & Rs $51.855,00$ \\
\hline 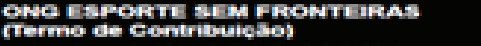 & $=$ & RS 25.000 .00 \\
\hline $\begin{array}{l}\text { LNaA CAMPist A DE DESAPORTOS } \\
\text { (Campeonatos locals) }\end{array}$ & O4 MESES & RS 93.772 .80 \\
\hline $\begin{array}{l}\text { PRO HANO ESPORTE - DE MAOS } \\
\text { DAOAS }\end{array}$ & o7 ME:5es & RES 179.909 .93 \\
\hline $\begin{array}{l}\text { ASSOCIACAO DE CAROEIRA ARTES E } \\
\text { CULTURAS DO NORTE FLUMINIENSEE }\end{array}$ & O6 Misses & RS 60.000 .00 \\
\hline $\begin{array}{l}\text { AsSOCIACAO DE DEMCIENTES } \\
\text { visuAIS DE CAMIPOS }\end{array}$ & OS MESES & RS $60.000,00$ \\
\hline Total & & R56600650234 \\
\hline
\end{tabular}

Fonte: Borba e Lira (2015).

Esse modelo de gestão pública e sua relação com entes privados foi objeto de críticas tanto do segmento acadêmico como de setores políticos da sociedade. E, esse movimento crítico desencadeou a eleição de uma nova gestão municipal que tinha como slogan combater a "velha política”. A gestão (2016-2020) assumiu o governo num contexto em que o orçamento municipal teve uma queda de quase 1 bilhão de reais e, com o novo orçamento, as medidas adotadas têm sido estratégias de parcerias público-privado. Entretanto, o discurso da atual gestão é de um movimento contrário ao anterior. O poder público ao invés de fomentar o setor privado pretende captar recurso do setor privado, mesmo porque essa gestão tem como desafio a queda das rendas petrolíferas.

\section{Estrutura organizacional do esporte do município de Campos}

A partir do Decreto $n^{\circ}$ 80/2015 o esporte campista foi vinculado à Secretaria de Educação, Cultura e Esportes (SMECE). Segundo 
informações do gestor da pasta, essa vinculação ocorreu em razão da relação do esporte com a educação e em razão da importância do trabalho conjunto e complementar entre as pastas. $\mathrm{O}$ governo tem buscado integrar o trabalho da educação e do esporte no olhar estratégico das políticas públicas com crianças, jovens e adultos por meio do desenvolvimento de ações durante o contra turno escolar.

De acordo com o levantamento dessas ações na cidade de Campos, há uma integração das atividades esportivas realizadas nos diferentes espaços de esportes e a rede escolar do município. Isso se dá por meio de uma ação conjunta entre a SMECE, escolas, centros esportivos e Fundação Municipal do Esporte (FME) - que realiza o trabalho de coordenação da área do esporte. À FME são atribuídas as seguintes funções e competências:

I - definir e implementar as políticas municipais de esportes e lazer, em consonância com as diretrizes estabelecidas no plano de governo, nas legislações municipal, estadual e federal pertinentes e observando ainda, as orientações e as deliberações do Conselho Municipal de Esporte;

II - definir e implementar as políticas de esportes e lazer para democratizar o acesso ao esporte e lazer no Município;

III - orientar sobre o gerenciamento dos recursos financeiros alocados no Fundo Municipal de Esportes;

IV - coordenar a realização de projetos, eventos, atividades e expressões de cunho esportivo e de lazer;

$\mathrm{V}$ - propor e gerenciar convênios com instituições públicas ou privadas em consonância com os objetivos que definem as políticas de esporte e lazer;

VI - coordenar outras atividades destinadas à consecução de seus objetivos; VII - realização de outras atividades correlatas.

E, para o desenvolvimento do trabalho, a FME conta com os seguintes equipamentos públicos esportivos:

- Sete Centros Escola Dos Esportes (CEDEs);

- Uma Sede da Fundação, espaço com estrutura de quadras, piscinas e sala para aulas de artes marciais, dança e ginástica;

- Cerca de 50 campos de futebol amador;

- Praças Públicas (Jardim São Benedito, Praça Santo Antônio e Praça da Lapa, por exemplo).

\section{Programa Viva o Esporte}

Diante da relação do esporte com a qualidade de vida e com o bemestar do indivíduo e das demandas crescentes da sociedade pelo direito ao esporte as gestões municipais não podem prescindir da política esportiva. Nesse sentido, a partir da nova gestão municipal, em 2017, deu-se início a ações políticas diferenciadas no desenvolvimento esportivo do município, 
por exemplo, a criação do Programa Viva o Esporte. Cabe ressaltar que, com a criação desse Programa, a prefeitura deixou de financiar entidades privadas e passou a ser a única responsável pela promoção do esporte no município.

O Programa Viva o Esporte tem como prioridade atender alunos da rede pública de ensino, mas também recebe cidadãos interessados em alguma prática esportiva, mesmo que não estejam matriculados em alguma escola. O Programa atende pessoas de faixas etárias e necessidades diferenciadas, recebe crianças a partir dos seis anos de idade, jovens, adultos e idosos.

O atual governo recebeu da gestão passada uma ampla rede de equipamentos com capacidade para atividades esportivas. Dentre esses equipamentos estão as praças, os campos de futebol amador e as chamadas Vilas Olímpicas - renomeadas como Centro Escola dos Esportes. Com a criação do Viva o Esporte os espaços públicos de promoção do esporte foram dinamizados no Município de Campos e o número de participantes amplamente aumentados, como demostrado no quadro a seguir:

Quadro 1 - Relação de Usuários das Políticas públicas voltadas ao Esporte em 2016 e 2018.

\begin{tabular}{|l|l|}
\hline Ano de 2016 & Ano de 2018 \\
\hline - 390 Profissionais Educadores & - 210 Profissionais Educadores \\
- 1.200 Inscritos & - 15.000 Inscritos \\
- Média de 01 profissional para & $\begin{array}{l}\text { Média de 01 Profissional para cada } 71 \\
\text { - cada } 03 \text { usuários. }\end{array}$ \\
\hline
\end{tabular}

Fonte: PMCG - FME (2018).

Portanto, diante das informações levantadas do Programa foi realizada uma análise de seu desenvolvimento nos anos de 2017 e 2018. Essa análise se deu por meio do método de avaliação CIPP, desenvolvido por Stuflebean (2003).

Sobre o Contexto do Programa Viva o Esporte, foi verificado que ocorreu uma demanda por parte da sociedade para as práticas esportivas, pois os espaços já existentes estavam sendo subutilizados. A gestão municipal anterior não era o agente fomentador dessas práticas e somente fazia o repasse de verbas para entidades esportivas privadas e ONGs, responsáveis pela execução das atividades de esporte.

Ao avaliar os Insumos do Programa, verifica-se que o Município de Campos dos Goytacazes apresenta uma infraestrutura de espaços esportivos satisfatória, composta de ginásios de esportes, quadras poliesportivas, quadras de areia, campos de futebol, piscinas, pistas de atletismo e locais de práticas de artes marciais, dança e ginástica. 
O número de inscritos nas modalidades esportivas oferecidas pelo município passou em dois anos de 1.200 para 15.000 , um crescimento expressivo. Outro fato relacionado ao aumento no número de inscritos está no incremento do número de modalidades esportivas e paraesportivas, como demonstra o Quadro 2.

Quadro 2 - Relação das Modalidades Esportivas ofertadas em 2016 e 2018.

\begin{tabular}{|l|l|}
\hline Ano de 2016 & Ano de 2018 \\
\hline - 9 Modalidades Esportivas & - 41 Modalidades Esportivas \\
- Nenhuma modalidade Paraesportiva & - 14 Modalidades Paraesportivas \\
\hline
\end{tabular}

Fonte: FME (2018).

A nova gestão da FME teve como desafio incrementar a participação da população nas atividades esportivas, principalmente de crianças em idade escolar, mas também não deixou de lado a população adulta, contemplada com inúmeras atividades esportivas e físicas. Depois de reuniões com a equipe técnica da FME e avaliação dos locais de práticas esportivas (praças, ginásios de esportes, quadras, campos de futebol e clubes esportivos) chegou-se a um número de ofertas de atividades esportivas que poderiam ser praticadas nesses espaços.

Os referidos espaços passaram previamente por reformas e melhorias para uma melhor utilização como local de prática esportiva. Posteriormente, verificou-se a capacitação profissional dos responsáveis pelas modalidades e a captação dos participantes do Programa a partir de campanhas publicitárias em vários meios de comunicação e mídias. $\mathrm{O}$ presidente da FME afirma que o aumento no número de participantes no Programa Viva o Esporte foi resultado da massiva campanha junto à comunidade escolar, campanhas em mídias eletrônicas e site oficial da prefeitura municipal, além de visitas aos estabelecimentos de ensino da cidade (THUIN, 2019).

As atividades do Programa são gratuitas e quando os pais realizavam as inscrições dos filhos nas atividades eram convidados a também participarem. Isso incrementou significativamente a participação dos adultos nas modalidades propostas. Outro fator que contribuiu para o aumento do número de inscritos foi a possiblidade do interessado poder participar de mais de uma modalidade, gerando nova inscrição para a contagem geral de participantes.

Avaliando os Processos do Programa Viva o Esporte, verificou-se que muitos locais de práticas esportivas não se encontravam em condições de uso, principalmente no aspecto da segurança dos usuários. Muitos desses locais e equipamentos estavam deteriorados pelo tempo e pelo uso incorreto. Outra constatação foi o grande número de profissionais envolvidos para poucos praticantes. 
Ao analisar-se o Produto da política esportiva é importante salientar que o foco do Programa foi dinamizar a prática do esporte e as atividades físicas da população campista. Ao se tratar dos esportes, especialmente para a população em idade escolar, o objetivo foi o aprendizado de uma ou mais modalidades e não a formação de equipes esportivas - o que naturalmente acontece com os alunos que se destacam nas diferentes modalidades. A média das práticas realizadas por aluno foi de duas modalidades esportivas, fato relevante tendo em vista a característica atual dos maus hábitos de atividade física da população, tanto infantil quanto adulta.

Cabe ressaltar que comparar o desenvolvimento do Programa Viva o Esporte nas duas gestões municipais se tornou relevante. Estudos realizados sobre as duas gestões demonstram que a primeira - apesar do grande dispêndio de recursos da Fundação Municipal de Esportes por meio de convênios, subvenções, termos de contribuição a entidades desportivas e ONGs - apresentava apenas 1,9\% da população beneficiária da política pública de esporte (BORBA; LIRA, 2015). Já a segunda gestão, apresentada nesse estudo, aumentou intensamente esse atendimento.

Porém, a partir de 2017, com a entrada de um novo grupo gestor na FME, implementar políticas de incentivo e fomento ao esporte tornou-se desafiador. Com um orçamento de praticamente 2 milhões a menos em relação a 2016, a equipe gestora da Fundação relatou que tem buscado não depender exclusivamente dos recursos municipais para desenvolver sua política esportiva. Isso tem sido buscado por meio de parcerias públicoprivada, parcerias com clubes locais, leis de incentivo ao esporte e emendas parlamentares.

\section{Considerações finais}

O investimento em política pública de esporte por parte dos governos locais pode ser compreendido por duas vertentes. Uma por entender a demanda crescente da sociedade por direito às práticas esportivas, pela necessidade de ocupação do tempo livre das crianças e jovens e pela busca da qualidade de vida dos adultos e idosos; outra pela visibilidade que esses investimentos podem trazer aos governos locais.

No caso da política de esporte colocada em prática a partir de 2017, no Município de Campos dos Goytacazes, encontra-se essas duas realidades. Se por um lado a sociedade clama pelo direito à ocupação organizada dos espaços públicos de convivência esportiva, como praças, quadras poliesportivas e campos de futebol, por outro o poder público apresenta uma resposta a esse movimento e alcança, inclusive, uma programática política eleitoral.

O rompimento com o modelo de repasses das verbas públicas a entidades privadas, alvo de críticas da gestão anterior, otimizou a utilização 
dos equipamentos de esporte-como os Centros Escola dos Esportes, antigas Vilas Olímpicas, por exemplo -, além de aumentar significativamente a oferta de atividades esportivas e o número de participantes. Contudo, o grande desafio da política de esporte no município e no País de forma geral é a continuidade desses programas. A cada governo, vê-se os orçamentos inflarem ou diminuírem de acordo com os interesses e orientações políticas dos gestores.

Torna-se, portanto, muito importante fomentar a política pública de esporte com seus diferentes significados e objetivos, utilizando-a como ferramenta possível de desenvolvimento do indivíduo e da comunidade. O esporte está muito além de uma simples prática esportiva, ele pode possibilitar a melhoria da qualidade de vida, do bem-estar geral, contribuir para a socialização, diminuir riscos sociais como a pobreza, violência, desemprego e melhorar a educação.

\section{Referências}

ANDERSEN, L. B. et al. Physical Fitness in relation to transport to school in adolescent. Scandinavian Journal of medicine and Science in Sport, Hoboken, NJ, USA, v. 19, n. 3, p. 406-411, 2009.

BARBANTI, V. O que é esporte? Revista Brasileira de Atividade Física e Saúde, Florianópolis, v. 11, n. 1, p. 54-58, 2006.

BENTO, J. O. Desporto: discurso e substância. Belo Horizonte, Campo das Letras, 2013.

BORBA, R. C.; LIRA, R. A. Esporte e lazer para que e para quem? Análise das políticas de esporte e lazer do Município de Campos dos Goytacazes (triênio 20122014). Globalização em Tempos de Regionalização: repercussões no território, 9 a 11 set. 2015, Santa Cruz do Sul. Anais [...] Santa Cruz do Sul, 2015. Disponível em: http://online.unisc.br/acadnet/anais/index.php/sidr/article/view/13373. Acesso em: 30 out. 2018.

BRAGA, T. M.; SERRA, R.; TERRA, D. C. T. Sobre financiamento e desenvolvimento institucional nos municípios petro-rentistas da Bacia de Campos. In: PIQUET, R.; SERRA, R. (org.). Petróleo e Região no Brasil: o desafio da abundância. Rio de Janeiro: Garamond, 2007.

BRASIL. IBGE Cidades. Portal virtual. [2018]. Disponível em: https://cidades. ibge.gov.br/brasil/rj/campos-dos-goytacazes/panorama. Acesso em: 30 out. 2018.

BRASIL. Constituição (1988). Constituição da República Federativa do Brasil. Brasília, DF: Senado Federal. Brasília, DF, 1988. Disponível em: https://www2. senado.leg.br/bdsf/bitstream/handle/id/508200/CF88_EC85.pdf. Acesso em: 20 nov. 2018.

FUNDAÇÃO MUNICIPAL DE ESPORTES (FME). PMCG: acervo de fotos de eventos esportivos promovidos pela FME. [2018]. Disponível em: www. campos.rj.gov.br. Acesso em: 10 set. 2018. 
HEDLEY, A. et al. Prevalence of overweight and obesity among US children, adolescents, and adults, (1999-2002). Journal American Medical Association, Chicago, v. 291, n. 23, p. 2.847-2.850, 2004.

INFOROYALTIES. Portal virtual. [2018]. Disponível em: inforoyalties.ucamcampos.br/. Acesso em: 20 nov.2018.

ÍNDICE DE DESENVOLVIMENTO DA EDUCAÇÃO BÁSICA (IDEB). Portal virtual. [2018]. Disponível em: http://portal.inep.gov.br/ideb. Acesso em: 20 nov. 2018.

MASSON, C. R. et al. Prevalência de sedentarismo nas mulheres adultas da cidade de São Leopoldo, Rio Grande do Sul, Brasil. Caderno Saúde Pública, São Paulo, n. 21, p. 1.685-1.694, 2005.

MATTA, L. G. da; BERÇOT, L. C.; RANGEL, L. C. As interconexões de ordem sócio-político e econômicas e seus rebatimentos no resultado do IDEB: um estudo de caso no município de Campos dos Goytacazes. VÉRTICES, Campos dos Goytacazes, v. 20, n. 2, p. 224-238, maio/ago. 2018. Disponível em: http://www. essentiaeditora.iff.edu.br/index.php/vertices/article/view/9073. Acesso 18 nov. 2018.

MELO, M. A. Estado, governo e políticas públicas. In: MICELI, S. (org.). O que ler na Ciência Social Brasileira, (1970-1995). São Paulo: Anpocs, 1999. p. 59-100.

PREFEITURA MUNICIPAL DE CAMPOS DOS GOYTACAZES (PMCG). Portal virtual. (2018). Disponível em: www.campos.rj.gov.br. Acesso em: 10 set. 2018.

PREFEITURA MUNICIPAL DE CAMPOS DOS GOYTACAZES (PMCG). Orçamento da FME - 2014 a 2017. (2018). Disponível em: https://transparencia. campos.rj.gov.br/orcamento-ldo. Acesso em: 11 set. 2018.

PREFEITURA MUNICIPAL DE CAMPOS DOS GOYTACAZES (PMCG). Câmara Municipal. Dispõe sobre a Política Municipal do Esporte e Lazer e dá outras providências. Decreto no 8.240, de 30 de junho de 2011. Disponível em: http://www.camaracampos.rj.gov.br/images/legislacao/leismunicipais/esporte/ Lei-8.240.pdf. Acesso em 19 nov. de 2018.

PREFEITURA MUNICIPAL DE CAMPOS DOS GOYTACAZES (PMCG). Dispõe sobre a alteração de cargos comissionados e funções gratificadas do poder executivo municipal, e dá outras providências. Decreto no 80/2015, de 16/04/2015. Disponível em: https://leismunicipais.com.br/a/rj/c/campos-dos-goytacazes/ decreto/2015/8/80/decreto-n-80-2015-dispoe-sobre-a-alteracao-da-estruturade-cargos-comissionados-e-funcoes-gratificadas-do-poder-executivo-municipale-da-outras-providencias. Acesso em: 11 set. 2018.

PREFEITURA MUNICIPAL DE CAMPOS DOS GOYTACAZES (PMCG). Câmara Municipal. Lei Orgânica Municipal. Publicada em 26/08/2014 e republicada em 29/08/2014. Disponível em: http://www.camaracampos.rj.gov. br/images/legislacao/leiorganicamunicipal/leiorganica.pdf. Acesso em 19 nov. 2018.

SANTOS, E. S. dos; STAREPRAVO, F. A.; SOUZA NETO, M. da S. Programa Segundo Tempo: o vazio assistencial na região Nordeste. Movimento, Porto Alegre, v. 2, n. 21, p.759-771, Trim. jul. 2015. Disponível em: https://seer.ufrgs.br/ Movimento. Acesso em: 2 maio 2019. 
SILVA, M. A. M. et al. Prevalência de fatores de risco cardiovasculares crianças e adolescentes da rede de ensino da cidade de Maceió. Arquivo Brasileiro de Cardiologia, Maceió, v. 84, n. 5, p. 387-92, maio 2005.

STAREPRAVO,F.A. Políticas públicas para o esporte e lazer: conselhos municipais de esporte e lazer e outras formas de participação direta. In: CONGRESSO BRASILEIRO DE CIÊNCIAS DO ESPORTE, XV., 16 set. 2007, Recife. Bienal. Disponível em: http://www.cbce.org.br/docs/cd/listaresumos.htm. Acesso em: 27 abr. 2019.

STAREPRAVO, F. A.; MEZZADRI, F. M. Algumas contribuições de Pierre Bourdieu e Norbert Elias à discussão das políticas públicas para o esporte e lazer. In: SIMPÓSIO INTERNACIONAL PROCESSO CIVILIZADOR, $\mathrm{X}$, Anual, $1^{\circ}$ abr. 2007. Campinas. Disponível em: http://www.uel.br/grupoestudo/ processoscivilizadores/portugues/sitesanais/anais10/trabalhos_geral.htm\#F. Acesso em: 27 abr. 2019.

STAREPRAVO, F. A. E assim criou-se a Rede: aspectos técnicos, políticos e epistemológicos envolvidos na criação de desenvolvimento da Rede Cedes. Movimento, Porto Alegre, v. 20, n. 1, p. 33-58, 2014.

STAREPRAVO, F. A.; et al. Programa esporte e lazer da cidade: onde o político/ burocrático e o científico/acadêmico se encontram? Movimento, Porto Alegre, v. 1, n. 23, p. 23-34, Trim. jan. 2018. Disponível em: https://seer.ufrgs.br/ Movimento. Acesso em: 29 abr. 2019.

STUFFLEBEAM, D. The CIPP Model for Evaluation: an update, a review of the model's development, a checklist to guide implementation. Paper read at Oregon Program Evaluators Network Conference, at Portland, Oregon. 2003. Disponível em: http://www.wmich.edu/evalctr/pubs/CIPP-ModelOregon10-03. pdf. Acesso em: 10 out. 2019.

THUIN, R. Fundação Municipal de Esporte e a política de esporte para Campos dos Goytacazes: projeto Viva o esporte, 2019. Presidente da FME de Campos dos Goytacazes. Disponível em: https://cidadesbr.com.br/2017/01/31/ fundacao-municipal-dos-esportes-de-campos-abre-7-mil-vagas-para-atividadesesportivas/. Acesso em 11 abr. 2019.

Submetido em: 13/08/2019

Aceito em: 01/10/2019 


\title{
LIVE SPORT: AN ANALYSIS OFTHE PUBLIC SPORTS POLICY OF A CITY INSIDE THE STATE OF RIO DE JANEIRO
}

\begin{abstract}
Public policies are guidelines for the action of the public power with society, norms and procedures for the relations of social actors and the state. The aim of this study was to describe and analyze the public sports policies of the Municipal Sports Foundation (FME), in the city of Campos dos Goytacazes/RJ. The methodology used was characterized as descriptive. The results of the study indicate that the municipality structures its work through the FME and that it has significant results in sports incentive policies. The sports programs offered by the municipality suffered a significant reduction in the number of physical education professionals between 2016 and 2018, however, there was an increase in the number of participants and offers of sports in the programs. In 2016 there were 1,200 participants in 9 modalities and in 2018 there were 15,000 participants and 41 modalities. Through the study, it was concluded that the public policy of the city of Campos dos Goytacazes focused on sports provides excellent results for the health and well-being of the population, including the reduction in health spending.
\end{abstract}

Keywords: Public policies. Sport. Recreation.

\section{DEPORTE EN VIVO: ANÁLISIS DE LA POLÍTICA DEPORTIVA PÚBLICA DE UN MUNICIPIO EN EL ESTADO DE RIO DE JANEIRO}

\section{Resumen}

Las políticas públicas son pautas para la acción del poder público con la sociedad, normas y procedimientos para las relaciones de los actores sociales y el estado. El objetivo de este estudio fue describir y analizar las políticas deportivas públicas de la Fundación Deportiva Municipal (FME), en la ciudad de Campos dos Goytacazes/RJ. La metodología utilizada se caracterizó como descriptiva. Los resultados del estudio indican que el municipio estructura su trabajo a través del FME y que tiene resultados expresivos en las políticas de incentivos deportivos. Los programas deportivos ofrecidos por el municipio sufrieron una reducción significativa en el número de profesionales de educación física entre 2016 y 2018, sin embargo, hubo un aumento en el número de participantes y ofertas de deportes en los programas. En 2016 hubo 1,200 participantes en 9 modalidades y en 2018 hubo 15,000 participantes y 41 modalidades. A través del estudio, se concluyó que la política pública de la ciudad de Campos dos Goytacazes centrada en el deporte proporciona excelentes resultados para la salud y el bienestar de la población, incluida la reducción del gasto en salud.

Palabras clave: Políticas públicas. Deporte. Ocio. 